\title{
Decisões em crise num domingo de manhã
}

\section{PAULA VARANDA}

Título: Do bosque para o mundo. Concepção e dramaturgia: Inês Barahona e Miguel Fragata. Texto: Inês Barahona. Encenação: Miguel Fragata. Interpretação: Anabela Almeida e Manuela Pedroso. Cenografia e figurinos: Maria João Castelo. Música original: Teresa Gentil. Desenho de luz: José Álvaro Correia. Direcção técnica: Nuno Figueira. Produção executiva: Formiga Atómica/Clara Antunes. Design gráfico (mapa): UVA atelier. Co-produção: Formiga Atómica e São Luiz Teatro Municipal (versão portuguesa) I Formiga Atómica e Théâtre de la Ville (versão francesa). Local e data de estreia: São Luiz Teatro Municipal, Lisboa, 22 de Novembro de 2016 (versão portuguesa); Théâtre de la Ville, Paris, 20 de Maio de 2017 (versão francesa).

Domingo de manhã. Apressada, subo a estação do metro com a minha filha: «Vamos lá... acho que vais gostar...», digo eu. Mas ela, renitente, atrasa o passo. Preferia, claro está, o conforto do lar e ver animes no iPad. Na rua, um dia de sol contrasta com a sala-estúdio do Teatro Municipal São Luiz, onde entramos: escura e um pouco abafada. Compreendo que não partilhe a minha devoção de convertida às artes, mas não podíamos perder esta oportunidade: «os artistas são muito bons», digo-lhe, «e é uma peça sobre crianças de outra parte do mundo, vai ser especial...»; tento justificar pouco, para não estragar a surpresa. ${ }^{1}$

Enquanto nos sentamos, entre outros adultos acompanhados de crianças e jovens, duas mulheres conversam baixinho, no palco, junto a uma pilha de malas e objectos. Quando a sala sossega, elas levantam-se e vêm à boca de cena falar connosco. Têm um ar amigável. Um sorriso terno. «Cada pessoa tem uma história. A sua história», diz uma mulher. A outra vai apontando para as pessoas no público - «Tu tens a tua história. Tu tens a tua história.... ${ }^{2}$

As duas actrizes falam do tempo em que somos crianças e alguém está lá, ao nosso lado, para dizer o que fazer, tomando decisões por nós; desse tempo em que nos contam histórias antigas e conhecidas, que

121 de Janeiro de 2018, na reposição da peça na Sala Mário Viegas do São Luiz Teatro Municipal.

2 Todas as citações, salvo indicação em contrário, são das vozes das duas actrizes, conforme o texto original do espectáculo facultado pelos directores da companhia. 
formam a nossa visão sobre a sociedade e o mundo, cultivando um sentido de moral e de justiça, partilhado colectivamente, e que informará as nossas ambições. Mas um dia saímos de casa e passamos a ter mesmo de fazer as nossas escolhas.

Assim se introduz Do bosque para o mundo, peça de teatro que Miguel Fragata e Inês Barahona criaram em 2016, após prolongada pesquisa sobre os contos que se contam às crianças de hoje. ${ }^{3}$ Conforme disseram à imprensa na altura, interessava-lhes observar as narrativas algo estranhas e peculiares que vêm do passado e persistem, contadas e recontadas, transmitindo valores e formando imaginários. Mas quais valores? Com que objectivos e com que forma? Contos que nos apresentam o belo e o feio, o bom e o mau, e que nos preparam para lidar com o temível ou o inesperado. Neste tempo, dado à pesquisa sobre as narrativas mais adequadas para preparar as crianças do século XXI para a vida adulta, soou um alarme estridente: a realidade de milhões de crianças refugiadas e desprotegidas. O casal decidiu então focar o seu trabalho nesta questão e, como explica Miguel Fragata numa entrevista, «queremos abrir espaço para que adultos e crianças possam falar sobre este tema, que está tão próximo e presente na nossa realidade, aqui ao lado, e muitas vezes sentimos que há uma pressão para esconder debaixo do tapete». ${ }^{4}$ Desta forma, iriam também contrariar a recente tendência de higienização dos contos tradicionais para a infância, com a limpeza de conteúdos controversos ou perturbadores enquanto as notícias, da realidade do quotidiano, trazem às crianças histórias terríveis, não raras vezes sobre outras crianças em vidas críticas, em outros lugares do mesmo mundo.

Manuela Pedroso e Anabela Almeida vão contar a história de Farid, um rapaz afegão, cuja família pertence ao povo pashtun, que vive sobre as regras restritas das Pashtunwali. Regras que não estão escritas, mas que todos seguem há séculos. As duas actrizes desenrolam um tapete e dispõem malas em cena, ao som de uma melodia oriental, marcando o início da história. Enquanto nos apresentam membros da família de Farid e as suas rotinas quotidianas, vão mudando a organização das malas no espaço. Bonitas malas vintage, trolleys modernos e malinhas necéssaire representam avós, mãe, pai, irmãs e tios; e duas mochilas de pano verde-tropa «são» Farid e Reza, o seu irmão mais velho. Esta coreografia

3 Sinopse, créditos, biografias, dossiê de imprensa e fotografias disponíveis no seu site, http:// formiga-atomica.com/espetaculos/do-bosque-para-o-mundo.

4 Observador, 22 de Novembro de 2016, consultado em http://formiga-atomica.com/wp-content/uploads/2017/10/Do-Bosque-para-o-Mundo-CLIPPING.pdf. 


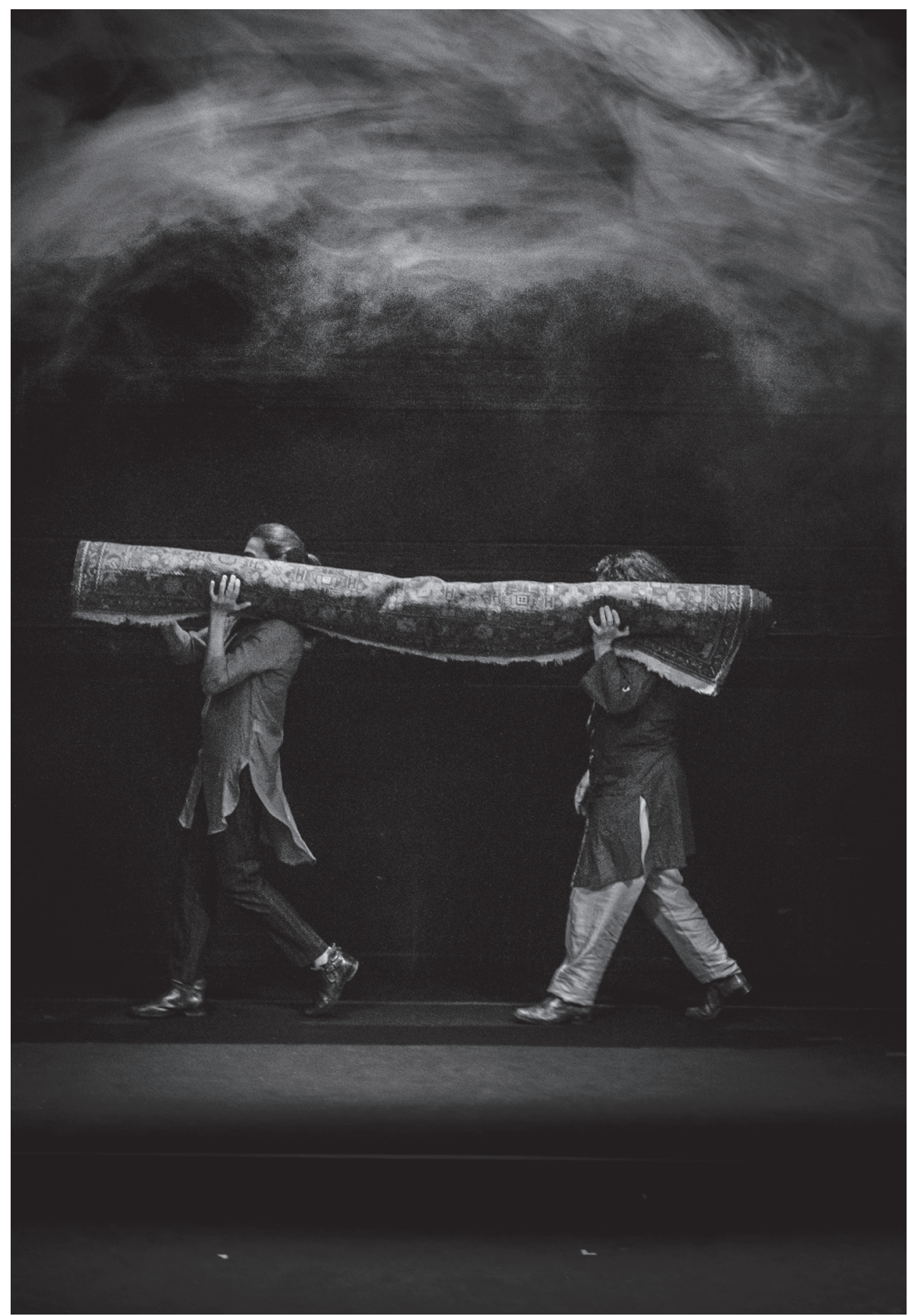

DO BOSQUE PARA O MUNDO, DE INÊS BARAHONA, ENC. MIGUEL FRAGATA, FORMIGA ATÓMICA, SÃO LUIZ TEATRO MUNICIPAL E THÉÂTRE DE LA VILLE, 2016/2017 (ANABELA ALMEIDA E MANUELA PEDROSO), [F] ESTELLE VALENTE/ /TEATRO SÃO LUIZ 
eficaz de malas que simbolizam pessoas facilita identificar quem faz o quê e o papel de uns e outros. Mas também é uma forma astuta de representar o que pertence ao passado ou ao espaço remoto, permitindo uma distância emocional, que é muito importante. Esta nãoé a nossa história, não apenas por uma questão de transferência pessoal - por exemplo, de uma mãe na plateia para uma actriz no palco. Esta é, felizmente, uma realidade distante deste grupo de espectadores porque, como veremos, é uma realidade de guerra; diluir essa distância em favor da empatia (que sim, é criada, mas com outros recursos performativos) poderia escamotear uma fronteira real.

Aqui a distância também é cultural; ela evidencia-se nos valores dos povos que seguem a Pashtunwali. As crianças não brincam na rua, não reclamam e não choram - isso são sinais de fraqueza, má educação e preguiça. A mulher fica em casa, toma conta do lar, não sai à rua sem um homem com ela e cobre sempre a cabeça - explicam as narradoras -; os rapazes vão à escola e as raparigas não.

De vez em quando, as duas mulheres param a azáfama de narradoras, olham à volta e abrem o espaço da reflexão; aquele espaço que é nosso, que partilhamos com elas, do presente, do teatro, do Ocidente, da liberdade; de quem observa a história alheia e depois vira um espelho para si próprio, para reconhecer a diferença de papéis sociais e de culturas. Lembram-nos elas que, para Farid, seria muito estranho ver duas mulheres, assim vestidas, em palco; mas, para nós, estranho seria elas estarem de cabeça tapada. A normalidade é diferente para uns e para outros. Assente esta verdade, a história continua.

Quando Farid tinha doze anos, tudo mudou na vida dele. Na tentativa de destruir Bin Laden e os Talibãs, o exército americano atacou o Afeganistão. As mulheres abrem duas malas e atiram roupas freneticamente para o ar enquanto contam os factos assustadores e comentam a posição ambígua dos americanos nesta guerra. Primeiro, ajudaram os Talibãs contra o governo russo; depois atacaram o Afeganistão para derrotar os Talibãs; e posteriormente, enquanto forças da ONU, compostas em grande parte por soldados americanos, vieram ajudar a reconstruir os escombros dessa guerra - «Mas há dois tipos de americanos? Há os americanos que destroem e os americanos que reconstroem?... isto é muito confuso», diz a Manuela, e a Anabela responde: «É a história do mundo. É o que temos.»

Suspeitando de armas escondidas pelos Talibãs em casa de Farid, os americanos invadiram e mataram o pai. Agora, segundo a Pashtunwali, 


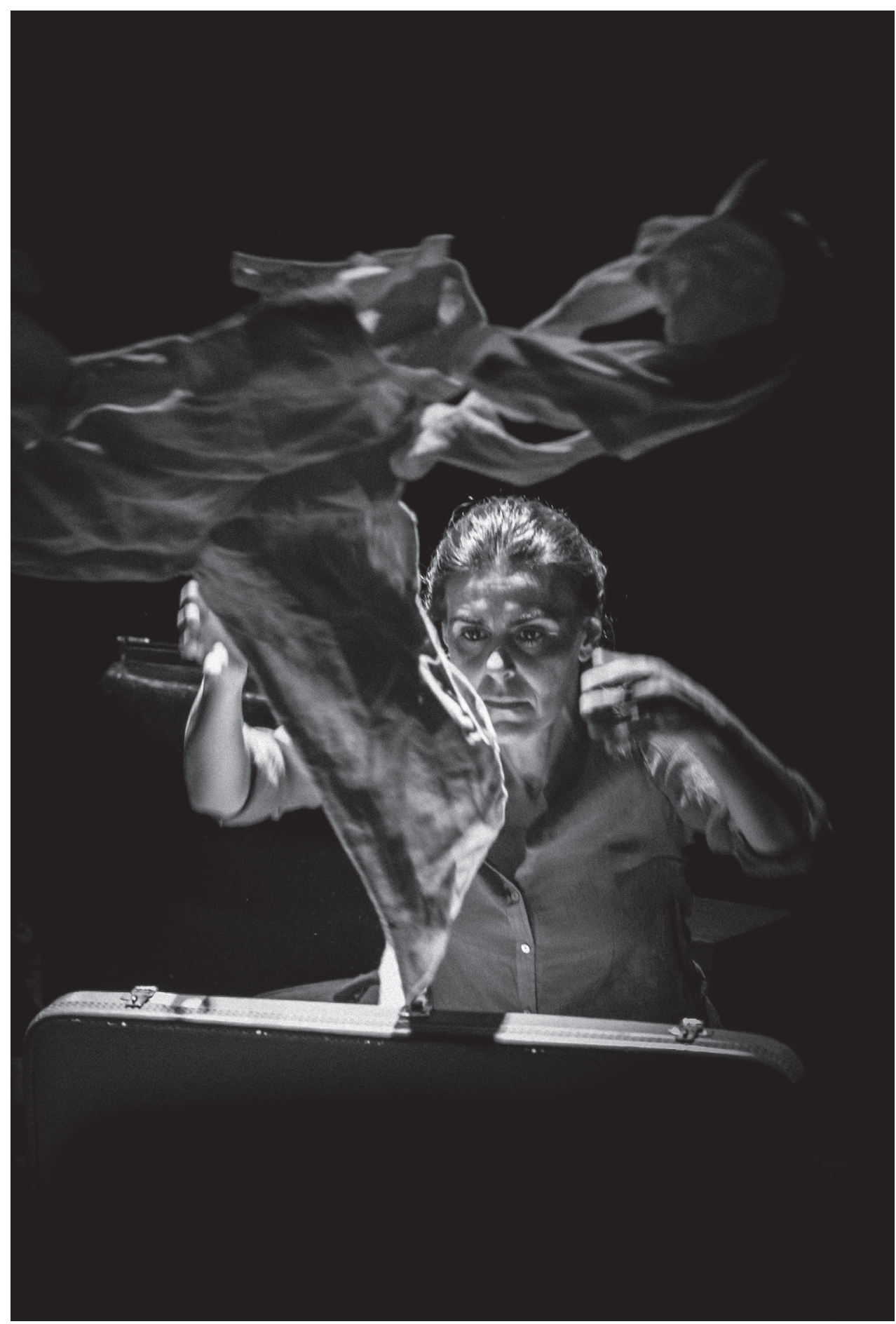

DO BOSQUE PARA O MUNDO, DE INÊS BARAHONA, ENC. MIGUEL FRAGATA, FORMIGA ATÓMICA, SÃO LUIZ TEATRO MUNICIPAL E THÉÂTRE DE LA VILLE, 2016/2017 (ANABELA ALMEIDA), [F] ESTELLE VALENTE/TEATRO SÃO LUIZ 
os dois filhos têm de se tornar terroristas e fazer-se explodir para matar americanos e assim vingar o pai. Manuela vira-se para Anabela, e depois para nós: «Consegues imaginar-te numa situação destas? Amarrar um cinto de explosivos ao corpo e explodir?» As duas pegam numa mala e noutra e noutra e andam de um lado para o outro, e chocam e trocam-se todas, sem saber para onde ir. É cómico. Até que se ouve um tiquetaque dentro de uma das malas - é uma bomba? Elas atiram a mala uma à outra como o jogo da batata quente. Faz rir. Uma atira a mala para o camarim. Pausa. Silêncio. BUM! A minha filha aperta-me o braço. É um gatilho performativo altamente eficaz: ficámos com medo por empatia com as narradoras, com o dilema das vítimas das bombas que elas evocavam e agora respiramos, profundamente, de alívio, também por empatia.

Embora claramente estruturada no género do conto oral, a peça é ágil a mergulhar as actrizes na narrativa, para incorporar a dualidade dos momentos críticos da indecisão e da crise de valores: o que era bom parece mau, a diferença entre certo e errado não é evidente, e o que é normal não parece. Quando nenhuma solução é boa, que devemos fazer? Como nos devemos sentir?

Movida pelo instinto, a mãe dos dois rapazes decidiu desafiar a tradição e mudar o destino dos filhos. Um tio manda-os vestir roupas quentes e ocidentais, arranja-lhes passaportes e dá uma mochila a cada um. A mãe entrega-lhes dinheiro e diz que vão viajar seis mil quilómetros com a ajuda de um desconhecido que garante uma viagem segura. Farid, com doze anos, não percebe nada. Tem medo e quer ir para casa. Sente-se um traidor mas, segundo a lei, não pode questionar as ordens da mãe: «Vocês vão partir. Têm de cuidar um do outro», disse ela. «Não largam as mãos um do outro NUNCA. E, aconteça o que acontecer, NUNCA voltam para trás.»

Tornados refugiados, os dois rapazes têm de atravessar sete países para chegar a Inglaterra e pedir asilo, ou serão mortos no próprio país. Manuela e Anabela explicam-nos que os países europeus são obrigados a aceitar refugiados. «É a Pashtunwali da Europa», diz Anabela. Viram costas e observam um mapa-mundo a descer em cena, lentamente, cobrindo o fundo do palco. Compreendemos a metáfora das mochilas. A viagem vai começar.

Claro que nada correu como previsto e os dois irmãos são logo separados mesmo antes de entrarem no primeiro avião. «Vais ver o teu irmão mais tarde»: dizendo isto, Manuela enterra a mochila de Reza num cesto de verga, com uma firmeza cruel, arrumando-o da história, para outra 


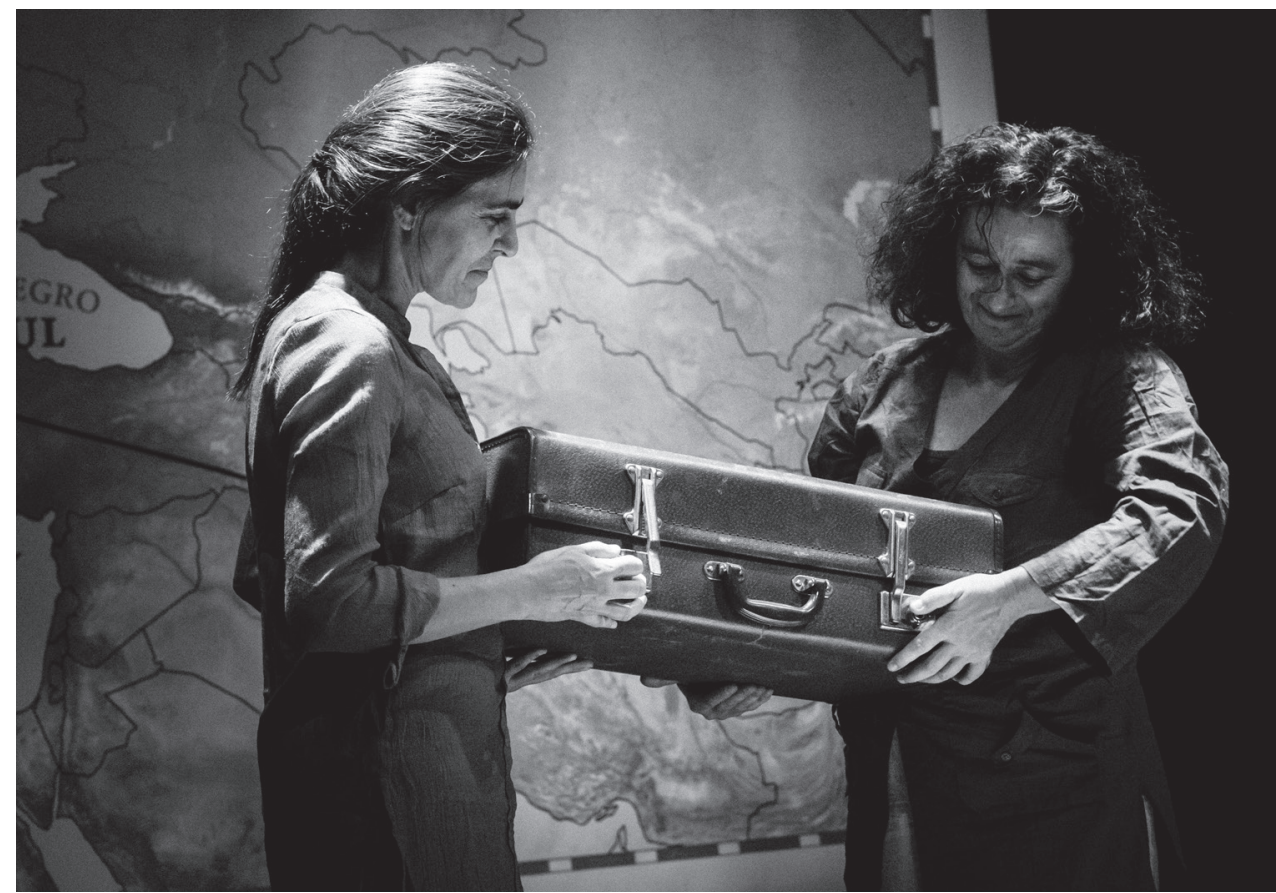

DO BOSQUE PARA O MUNDO, DE INÊS BARAHONA, ENC. MIGUEL FRAGATA, FORMIGA ATÓMICA, SÃO LUIZ TEATRO MUNICIPAL E THÉÂTRE DE LA VILLE, 2016/2017 (ANABELA ALMEIDA E MANUELA PEDROSO), [F] ESTELLE VALENTE/ /TEATRO SÃO LUIZ

história que não acompanharemos. Nós ficamos com Farid e com a sua terrível travessia de transporte em transporte, de esconderijo em esconderijo, perigosa e suja, com fome, obrigado a dar o passaporte sob ameaça de repatriamento ou prisão, extorquido pelos traficantes e sem nunca poder voltar para casa.

Com miniaturas de carros, camiões, pessoas e um barco, as montanhas de roupas que saíram das malas e outros objectos em cena, as narradoras trazem ao palco a experiência dessa viagem-pesadelo, alternando entre contar a história e sublinhar ou comentar os dilemas, as emoções e as aberrações destes acontecimentos. Sempre de forma suficientemente clara para se compreender o essencial, mas também sempre subtis, para que possamos nós escolher um percurso de aproximação ou distanciamento desta realidade colectiva, de outra parte do mundo, e da história de Farid, que é a história de muitas outras crianças. Para podermos, se quisermos, chegar muito perto de Farid, embora, por sagaz estratégia dramatúrgica, não haja ilusões: devemos conhecer a sua história e viver as suas emoções, mas não somos este rapaz. 
Ao longo da viagem, Farid percebe, em Roma, num abrigo de crianças refugiadas, que a Pashtunwali não é uma lei universal, pois ali brincar era normal; em Callais, a «Selva», duvida da palavra da mãe, que lhe prometera segurança e liberdade na Europa; e, quando o detêm na fronteira na Inglaterra, após cem tentativas de fuga, parece que afinal não há «Pashtunwali da Europa». Farid está prestes a ser deportado, no seguimento de um interrogatório ardiloso e ameaçador. Manuela e Anabela, fazendo de guardas de fronteira ou comentando o desfecho do episódio, rodeiam a pequena mochila de pano verde «sozinha»e «vulnerável» na cadeira. Passado um longo tempo de incerteza, uma mulher, funcionária, que assistia, calada, acredita nele e decide ajudá-lo; vai procurar o seu irmão, Reza, e tratar da legalização a que o rapaz tem direito, como criança refugiada de guerra.

Aprendemos aqui sobre a história dos outros, que acontece a muitos que vivem no mesmo tempo e no mesmo mundo que nós. Como esta é tão drasticamente dramática, também percebemos como é precioso viver em liberdade e segurança. E aprendemos que, se quisermos, podemos fazer alguma coisa. Alguma coisa que pode mudar o destino dos que têm a vida em perigo, ou dos que não vêem os seus direitos respeitados. Manuela conclui que «as nossas decisões também escrevem as histórias dos outros», e como diz Anabela: «Afinal, estamos todos juntos neste barco a que chamamos mundo.»

Do bosque para o mundo é direccionado originalmente para crianças maiores de dez anos, dada a co-produção do Programa São Luiz Mais Novos. Mas as crianças e jovens vão aos espectáculos acompanhados por adultos. Todos aprendemos. Se já sabíamos, quando voltamos a ver, a ouvir e a sentir, ao lado das crianças, apreende-se de outra forma. Dez meses mais tarde, quando escrevo este artigo, a minha filha ainda se lembra bem do espectáculo. Diz-me que gostou porque aborda de forma clara coisas difíceis «que, como tu sabes, eu não gosto de falar». Terrorismo e refugiados foram dois temas que chegaram à sua escola, quando a guerra civil na Síria se tornou visível, com a massiva migração em fuga até às fronteiras da Europa, em 2015, e foi diariamente noticiada. Ela tinha nove anos e ganhou um medo enorme do desconhecido, que a atormentou durante muito tempo. Finalmente, com este espectáculo, pudemos sentir juntas, conversar e entender melhor um assunto que se tinha tornado tabu.

A possibilidade de transformação, como resultado de fruir o espectáculo, é fruto da dramaturgia e da encenação, onde combinam habilmente 


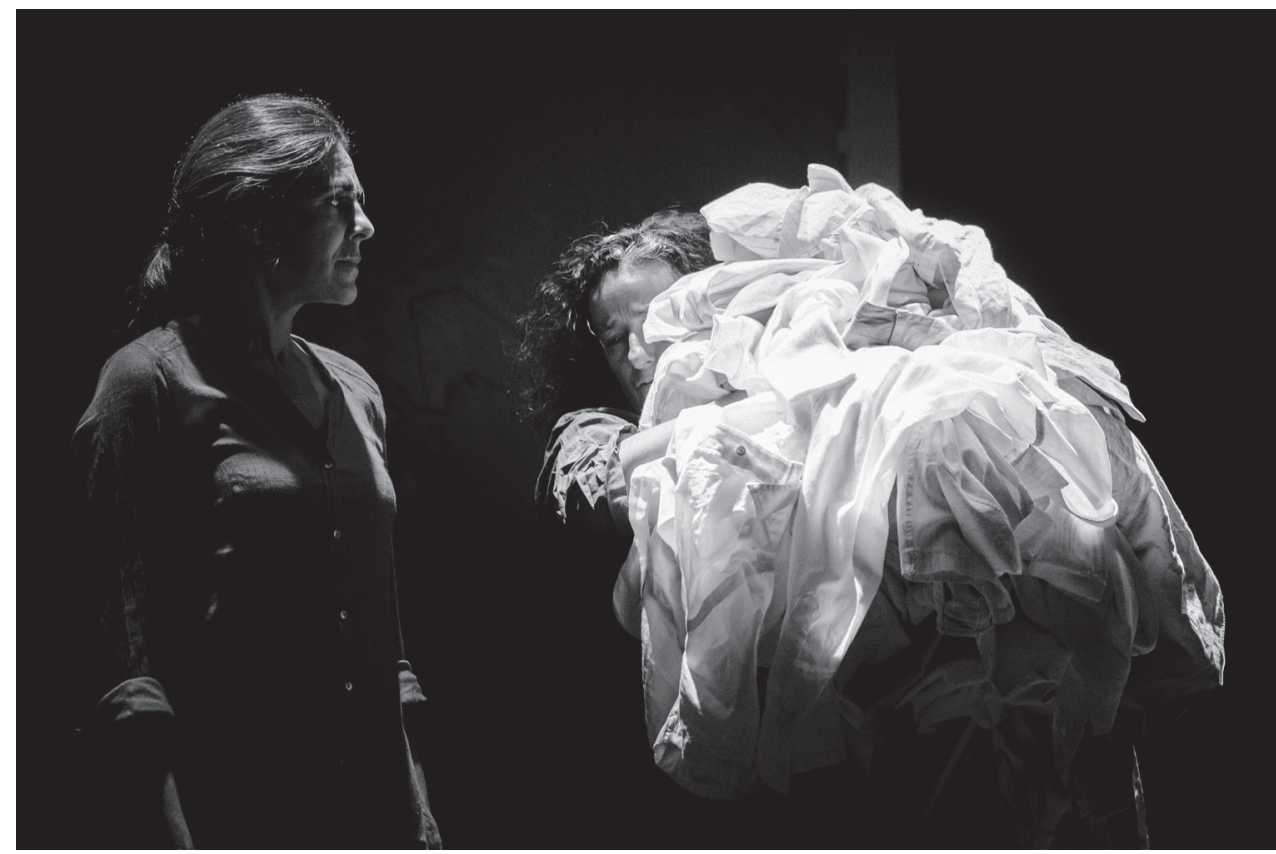

DO BOSQUE PARA O MUNDO, DE INÊS BARAHONA, ENC. MIGUEL FRAGATA, FORMIGA ATÓMICA, SÃO LUIZ TEATRO MUNICIPAL E THÉÂTRE DE LA VILLE, 2016/2017 (ANABELA ALMEIDA E MANUELA PEDROSO), [F] ESTELLE VALENTE/ TEATRO SÃO LUIZ

os elementos performativos, visuais e sonoros a par de uma cuidadosa gestão das emoções. Para a minha filha, as actrizes serem amigáveis e terem sentido de humor foi importante; e eu acrescento: uma actuação envolvida e generosa, mas contida e precisa. A passagem entre quatro estados - contar a história, representar a história, comentar a história e interrogar-nos durante a história - é sempre nítida e rápida. Elas estão conscientes do seu papel de intermediárias, que nos facilita envolver emocional, somática e racionalmente e ajuda a tomar, privadamente, posição sobre questões críticas do nosso tempo. Aqui, apenas pude trazer a amostra de um texto e encenação muito ricos.

Miguel Fragata e Inês Barahona sabiam que este conteúdo sensível levantaria questões complexas junto do público jovem, logo no teatro, em casa ou na escola, em conversa ou em pensamento. As questões associadas a direitos humanos e presas a dilemas de crenças e políticas foram deixadas em aberto, sublinhando que há decisões muito difíceis de tomar. Inês explica em entrevista desejarem «confiar na inteligência das crianças para que façam a sua leitura e a sua reflexão». Noutro tipo de questões, aparecem parênteses explicativos e educativos, que não quebram a 
imersão na peça: Talibãs, Bin Laden, Pasthunwali, Nações Unidas, refugiados, ilegal, terroristas, contrabando e traficante de humanos são palavras cujo significado em relação ao assunto é identificado, permitindo às crianças assimilarem um léxico colectivo do presente, que lhes é transmitido como na tradição do conto e da oralidade.

A peça estreou em Novembro de 2016, em Lisboa, e depois em Paris, na versão em francês, que fazia parte da encomenda. Circulou muito em Portugal durante 2017 e, no Verão de 2018, destacou-se no Festival D'Avignon. ${ }^{5}$ Em Setembro, voltou a Lisboa para integrar o Festival Todos. Com mais de setenta representações ${ }^{6}$, este conto já chegou a muitas crianças de contextos culturais e socioeconómicos muito diversos, da escola local à pequena cidade, à capital. É uma obra tão consistente quanto arriscada e um acto de bravura dos artistas envolvidos. O confronto com espectadores que conhecem de perto esta temática e experiências pode ser perturbador para quem assiste e para quem actua; e o meio profissional, académico e institucional relacionado estará sempre vigilante sobre uma abordagem artística desta natureza, que é cultural e diplomaticamente sensível e eticamente responsável.

Na minha posição de especialista em artes performativas, europeia de classe média a viver num país em paz e virado para o Atlântico, longe daquela rota de sofrimento, considero o trabalho o louvável resultado de uma intuição muito qualificada, que retoma a força política da arte teatral para contar histórias de vozes silenciadas. Sintonizados com o seu tempo, muitos projectos artísticos na Europa têm dado atenção à crise dos refugiados e da migração. Neste âmbito, onde Do bosque para o mundo se enquadra perfeitamente, os artistas tornam-se activistas com aquilo em que são mestres e produzem uma arte para a experiência, a reflexão e o diálogo importantes para complementar, ou afrontar, as iniciativas operacionais de políticas de salvamento, imigração e integração.

No Afeganistão, e não só, ainda há bombas a explodir e civis a fugir da morte. Esta obra teatral, que vai continuar a circular aqui e pelo mundo, é para acompanhar. Não percam esta oportunidade para reflectirem sobre o que nós podemos fazer. 